\title{
Risk Factors for Chronic Lung Disease and Mortality in Newborns with Congenital Diaphragmatic Hernia
}

\author{
L. van den Hout ${ }^{a} \quad$ I. Reiss ${ }^{a} \quad$ J.F. Felix ${ }^{b} \quad$ W.C.J. Hop ${ }^{c}$ Pamela A. Lally ${ }^{d}$ \\ Kevin P. Lally ${ }^{d} \quad$ D. Tibboel ${ }^{a}$ for the Congenital Diaphragmatic Hernia \\ Study Group \\ antensive Care and Department of Pediatric Surgery, Erasmus MC - Sophia, b Department of Epidemiology, \\ Erasmus MC, and 'Department of Biostatistics, Erasmus MC, Rotterdam, The Netherlands; ${ }^{\mathrm{d}}$ Department of Pediatric \\ Surgery, University of Texas Medical School and Children's Memorial Hermann Hospital, Houston, Tex., USA
}

\section{Key Words}

Congenital diaphragmatic hernia $\cdot$ Bronchopulmonary

dysplasia $\cdot$ Neonatal mortality

\begin{abstract}
Background: Congenital diaphragmatic hernia $(\mathrm{CDH})$ is associated with a mortality rate of $10-35 \%$ in live-born infants. Moreover, $\mathrm{CDH}$ survivors have a substantial risk of developing long-term pulmonary sequelae, such as bronchopulmonary dysplasia (BPD). Objectives: This study aims to evaluate risk factors associated with BPD and mortality in neonates with $\mathrm{CDH}$, with particular focus on the initial ventilation mode. Methods: Eligible for inclusion were live-born infants with CDH born from 2001 through 2006 at the centers participating in the CDH Study Group. BPD (defined as oxygen dependency at day 30) and/or mortality by day 30 served as the primary endpoint. Results: A total of 2,078 neonates were included in the analysis. At day $30,56 \%$ of the patients had either died or met the criteria for BPD. In infants who survived until day 30 , the prevalence of BPD was $41 \%$. The overall mortality rate was $31 \%$. High-frequency oscillatory ventilation as initial ventilation mode, a right-sided defect, a prenatal diagnosis, a lower Apgar score at $5 \mathrm{~min}$, a cardiac
\end{abstract}

anomaly, a chromosomal anomaly and a lower gestational age were all associated with BPD and/or mortality by day 30 . Conclusions: Despite improvements in neonatal care, the rates of BPD and early mortality in newborns with $\mathrm{CDH}$ are still considerable. Several important risk factors for a worse outcome are reported in this nonrandomized prospective observational study.

Copyright $\odot 2010$ S. Karger AG, Basel

\section{Introduction}

Congenital diaphragmatic hernia $(\mathrm{CDH})$ is a rare congenital anomaly which occurs in approximately 1 in every 2,500 live births [1]. It is associated with severe pulmonary hypoplasia and pulmonary hypertension. Mortality rates ranging from 10 to $35 \%$ have been reported, depending on case selection [1-5]. Survival rates have increased with improvements in neonatal care, including

See Appendix for the members of the writing committee of the Congenital Diaphragmatic Hernia Study Group as well as a full list of the centers that contributed to the Congenital Diaphragmatic Hernia Registry.

\section{KARGER}

Fax +41613061234 E-Mail karger@karger.ch www.karger.com
(C) 2010 S. Karger AG, Base

$1661-7800 / 10 / 0984-0370 \$ 26.00 / 0$

Accessible online at:

www.karger.com/neo
Dick Tibboel, MD, $\mathrm{PhD}$

Intensive Care and Department of Pediatric Surgery

Erasmus MC - Sophia, Room Sk-3286, Dr. Molewaterplein 60

NL-3015 GJ Rotterdam (The Netherlands)

Tel. +31 10703 6567, Fax +31 10703 6288,E-Mail d.tibboel@erasmusmc.n 
'gentle' ventilation strategies, delayed surgery and extracorporeal membrane oxygenation (ECMO) in selected cases [4-8]. However, survivors of $\mathrm{CDH}$ remain at high risk of developing secondary morbidity. Long-term pulmonary sequelae, such as chronic lung disease, persistent pulmonary hypertension, asthmatic symptoms and recurrent respiratory tract infections have been reported in $30-50 \%$ of cases [9-14]. Alarmed by this information, the American Academy of Pediatrics developed official guidelines for structural and interdisciplinary follow-up [15].

Bronchopulmonary dysplasia (BPD) is a chronic respiratory disorder presenting early after birth. It mostly occurs in premature infants or term infants who have acute pulmonary disease. Ventilator-induced lung injury and high concentrations of oxygen predispose newborns to develop BPD $[16,17]$. In newborns with $\mathrm{CDH}$, the severity of lung hypoplasia may also be predictive for the development of BPD $[13,14,18]$.

Research efforts have been directed at optimizing ventilation strategies for newborns with $\mathrm{CDH}$. The 'permissive hypercapnia' approach, for example, led to higher survival rates and less pulmonary morbidity [5, 19]. Around the world, newborns with $\mathrm{CDH}$ typically receive conventional ventilation, with high-frequency oscillatory ventilation (HFO) as rescue therapy. However, in certain cases HFO will serve as the initial ventilation mode [20]. Observational and retrospective studies have reported that $\mathrm{HFO}$ as an initial ventilation mode may be an effective method to reduce mortality and chronic lung disease in children with $\mathrm{CDH}[7,21-24]$. So far, no prospective trials have been carried out to determine if initial ventilation treatment with HFO may reduce long-term pulmonary sequelae. Moreover, most studies so far have focused on mortality and the need for ECMO rather than on chronic lung disease as outcome measures $[9,18,25]$.

The aim of this study is to describe possible risk factors for BPD and early mortality in infants with $\mathrm{CDH}$. More specifically, this study aimed to determine if the initial ventilation mode, either conventional ventilation or HFO, has some bearing on outcome.

\section{Methods}

\section{Patients}

We retrieved data from the large multi-institutional database of the CDH Study Group. This cooperative network of over 50 centers was established in 1995 to compile data on live-born children with CDH. Data on prenatal evaluation, mode of delivery, neonatal care, surgery and clinical outcome until hospital dis- charge or death are prospectively recorded on standardized registry forms and entered into a central database [26].

In the CDH Registry database, data on the mode and duration of ventilation were available from the year 2001 until the year 2006. Therefore, we only included children born between January 2001 and December 2006. The large majority had been treated with conventional ventilation or HFO as initial ventilation mode. The few newborns treated with high-frequency jet ventilation were excluded from the analysis. Newborns with central or bilateral CDH were excluded as well because their clinical course differs from that of those with more common left- or right-sided $\mathrm{CDH}$ [27].

For the purpose of this article, data from 64 centers were collected. Centers are arbitrarily coded in the CDH Registry database as 'high-volume' or 'low-volume' centers. High-volume centers are those that admit more than 10 newborns with $\mathrm{CDH}$ per year. Furthermore, centers were coded as ECMO centers or nonECMO centers.

The primary outcome measure in this study was BPD and/or mortality by day 30 . In addition, separate analyses were performed for mortality by day 30 and BPD. Jobe and Bancalari [28] have defined BPD as oxygen dependency at day 28 or at 36 weeks postmenstrual age, depending on the gestational age at birth. However, the $\mathrm{CDH}$ Registry database holds data on oxygen dependency at day 30 instead of day 28. This is why we used oxygen dependency at day 30 as the criterion for BPD. The severity of BPD is determined at day 56 or at discharge, whichever comes first [28]. However, this could not be determined since data on oxygen dependency at day 56 were not recorded in the CDH Registry. Data on oxygen dependency at discharge or transfer are presented in a descriptive way.

\section{Statistical Analysis}

To test associations between individual putative risk factors and outcome measures, univariate analyses were performed, using $\chi^{2}$ and Mann-Whitney $U$ tests where appropriate. Baseline variables that showed a significant effect in univariate analysis were entered into multiple logistic regression analyses for BPD and/or mortality by day 30 and BPD and mortality by day 30 separately using a stepwise backward elimination method. $\mathrm{p}$ values for trend over the study years for all 3 outcome measures were also calculated using logistic regression. As many data on medication for pulmonary hypertension and the position of the liver were missing, we did not use these variables in the statistical analysis. Results of the regression analyses are given as odds ratios with the 95\% confidence interval. Data were analyzed using SPSS 16.0 (SPSS Inc., Chicago, Ill., USA). A two-sided p value less than 0.05 was considered statistically significant.

\section{Results}

The $\mathrm{CDH}$ database held data on 4,466 patients born from 1995 onwards. Eligible subjects were those born between 2001 and 2006, a total of 2,134 children. Of these, 56 were excluded based on our exclusion criteria or incorrect data, leaving 2,078 subjects (fig. 1). Analysis revealed no significant differences in baseline patient characteris- 
Fig. 1. Flowchart of patient inclusion and exclusion in the present study. ${ }^{*} 2,120$ patients were born before 2001; 212 patients were born after 2006. ${ }^{* *}$ Due to bilateral $\mathrm{CDH}(\mathrm{n}=13)$, central CDH $(\mathrm{n}=4)$, highfrequency jet ventilation $(n=13)$ or incorrect data on survival $(n=26) .{ }^{* *}$ Data on $\mathrm{BPD}$ were missing for 75 patients.

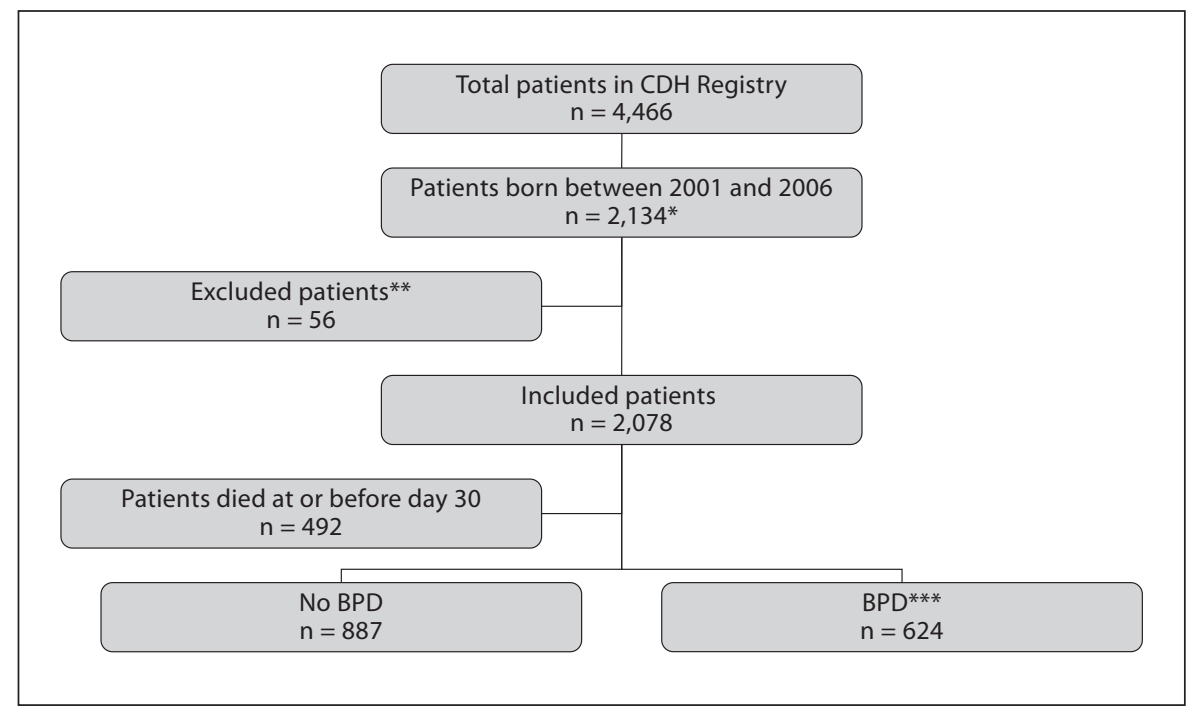

tics, the prevalence of BPD $(\mathrm{p}=0.762)$ or the survival rate $(\mathrm{p}=0.122)$ between the patients included in the study and patients who were born before $2001(\mathrm{n}=2,120)$. BPD and/ or mortality by day 30 was present in $56 \%(n=1,116 / 2,003$, missing data $=75)$ of the included patients and $58 \%(\mathrm{n}=$ $1,162 / 2,012$, missing data $=8$ ) of the nonincluded patients who were born before $2001(\mathrm{p}=0.144)$. Patient characteristics are shown in table 1.

\section{$B P D$ and Mortality by Day 30}

By day 30, 56\% of all the study infants ( $\mathrm{n}=1,116 / 2,003$, missing data $=75$ ) had either died or met the criteria for BPD. Mortality by day 30 was $24 \%(n=492 / 2,078)$. Overall mortality until hospital discharge for all 2,078 newborns was $31 \%(n=634 / 2,078)$. Of the newborns that survived until day $30,41 \%(n=624 / 1,511$, missing data $=75)$ met the criteria for BPD. Of these infants, $56 \%(\mathrm{n}=$ $344 / 612$, missing data $=12$ ) had mechanical ventilation, $9 \%(\mathrm{n}=57 / 612)$ had continuous positive airway pressure and $34 \%(\mathrm{n}=211 / 612)$ had a nasal cannula at day 30 . Of the infants that survived, $21 \%(\mathrm{n}=304 / 1,423$, missing data $=21)$ were oxygen dependent at discharge or transfer. Of these, $17 \%(n=51 / 295$, missing data $=11)$ were mechanically ventilated at discharge or transfer, $2 \%(n=$ $6 / 295)$ received continuous positive airway pressure and $81 \%(\mathrm{n}=238 / 295)$ had a nasal cannula.

The prevalence of BPD and/or death by day 30 did not change over the study period ( $\mathrm{p}$ for trend $=0.251$ ). The prevalences of mortality by day 30 and BPD separately also did not change significantly over the study period ( $\mathrm{p}$ for trend $=0.625$ and 0.317 , respectively).
Table 1. Baseline characteristics for all live-born patients with $\mathrm{CDH}(\mathrm{n}=2,078)$ born between 2001 and 2006

\begin{tabular}{lcc}
\hline Variable & $\begin{array}{l}\text { Number of } \\
\text { patients }\end{array}$ & $\%$ \\
\hline Males & $1,235 / 2,076$ & 59 \\
Birth in high-volume center & $1,132 / 2,078$ & 54 \\
Birth in ECMO center & $1,910 / 2,078$ & 92 \\
Inborn & $837 / 2,076$ & 40 \\
Vaginal delivery & $1,021 / 1,855$ & 55 \\
Prenatal diagnosis & $1,246 / 2,073$ & 60 \\
Cardiac abnormality & $322 / 2,077$ & 16 \\
Chromosomal abnormality & $89 / 2,077$ & 4 \\
Other abnormality ${ }^{1}$ & $176 / 2,078$ & 8 \\
Left-sided defect & $1,735 / 2,060$ & 84 \\
\hline Continuous variables & Median & Range \\
\hline Gestational age at birth, weeks & 38 & $23-42$ \\
Birth weight, kg & 3.03 & $0.57-4.90$ \\
Apgar score at 5 min & 7 & $0-10$ \\
\hline
\end{tabular}

Numbers do not always add up to 2,078 because of missing data.

${ }^{1}$ Other abnormality is classified as a congenital anomaly other than congenital heart disease or a chromosomal abnormality.

\section{Extracorporeal Membrane Oxygenation}

A total of 1,910 infants were born in an ECMO center. Overall, an ECMO procedure was performed in $29 \%$ of the patients $(n=595 / 2,078)$. The median day on which ECMO was started was the second day of life (range 
Table 2. Baseline patient characteristics for patients with $\mathrm{CDH}$ who received initial ventilatory treatment with HFO (n = 674) or CMV ( $\mathrm{n}=1,261)$

\begin{tabular}{lccrrr}
\hline Variable & HFO & $\%$ & CMV & $\%$ & p value \\
\hline Males & $391 / 674$ & 58 & $753 / 1,260$ & 60 & 0.485 \\
Birth in high-volume center & $398 / 674$ & 59 & $708 / 1,262$ & 56 & 0.230 \\
Birth in ECMO center & $651 / 674$ & 96 & $1,144 / 1,262$ & 91 & $<0.001$ \\
Inborn & $360 / 674$ & 53 & $422 / 1,260$ & 33 & $<0.001$ \\
Vaginal delivery & $312 / 588$ & 53 & $665 / 1,161$ & 57 & 0.104 \\
Prenatal diagnosis & $480 / 674$ & 71 & $673 / 1,261$ & 53 & $<0.001$ \\
Cardiac abnormality & $93 / 674$ & 14 & $203 / 1,261$ & 16 & 0.203 \\
Chromosomal abnormality & $33 / 673$ & 5 & $46 / 1,262$ & 4 & 0.226 \\
Other abnormality & $69 / 674$ & 10 & $92 / 1,262$ & 7 & 0.031 \\
Left-sided defect & $562 / 673$ & 84 & Median & Range & p value \\
\hline Continuous variables & Median & Range & 38 & $26-42$ & 0.126 \\
\hline Gestational age at birth, weeks & 38 & $26-42$ & 3.1 & $0.7-4.8$ & $<0.001$ \\
Birth weight, kg & 3.0 & $0.6-4.9$ & 7 & $0-10$ & $<0.001$ \\
Apgar score at 5 min & 7 & $1-9$ & & 84 & 0.819 \\
\hline
\end{tabular}

Numbers do not always add up to 1,935 because of missing data. CMV = Conventional mechanical ventilation.

${ }^{1}$ Other abnormality is classified as a congenital anomaly other than congenital heart disease or a chromosomal abnormality.

$0-129)$. The median duration of the ECMO treatment was 10 days (range $0-42$ ). A total of 283 patients (48\%) had surgical correction of the diaphragmatic defect during the ECMO treatment.

A total of $93 \%$ infants $(n=523 / 564$, missing data $=31)$ who underwent an ECMO procedure had either died by day 30 or met the criteria for BPD, compared with $41 \%$ of the infants $(\mathrm{n}=591 / 1,439$, missing data $=44)$ who did not undergo an ECMO procedure ( $\mathrm{p}<0.001)$. By day $30,38 \%$ of the patients who underwent an ECMO procedure had $\operatorname{died}(\mathrm{n}=212 / 564$, missing data $=31)$, compared to $19 \%$ ( $n=280 / 1,483)$ of the patients who did not undergo an ECMO procedure $(\mathrm{p}<0.001)$. Overall mortality after an ECMO procedure was $51 \%(n=285 / 564$, missing data $=$ 31 ). BPD was present in $88 \%$ of the patients who underwent an ECMO procedure and survived until day $30(\mathrm{n}=$ $311 / 352$ ), compared to $27 \%$ of the patients who did not undergo an ECMO procedure and survived until day 30 $(\mathrm{n}=313 / 1,159 ; \mathrm{p}<0.001)$.

\section{Surgical Repair}

A surgical repair was performed in $83 \%$ of all patients ( $n=1,729 / 2,078)$. The median day of surgical repair was the fourth day of life (range $0-112$ ). A patch repair, as op- posed to primary repair, was performed in $49 \%$ of the cases $(n=837 / 1,725$, missing data $=4)$.

Seventy-five percent of the infants ( $n=599 / 801$, missing data $=36$ ) who underwent a patch repair had either died by day 30 or met the criteria for BPD, compared with $20 \%$ of the infants $(n=171 / 854$, missing data $=34)$ who did not undergo a patch repair $(\mathrm{p}<0.001)$. Of the patients who underwent a patch repair, $16 \%(n=132 / 837)$ had died by day 30 , compared to $2 \%(n=18 / 888)$ of the patients who underwent a primary repair $(\mathrm{p}<0.001)$. BPD was present in $70 \%$ of the patients who underwent a patch repair and survived until day $30(n=467 / 669$, missing data $=36$ ), compared to $18 \%$ of the patients who underwent a primary repair and survived until day $30(\mathrm{n}=$ 153/852, missing data $=34 ; \mathrm{p}<0.001$ ).

\section{Initial Ventilation Mode}

Of all patients, $35 \%$ received $\mathrm{HFO}(\mathrm{n}=674 / 1,936)$ and $65 \%$ received conventional ventilation $(\mathrm{n}=1,262 / 1,936$, missing data $=142)$ as initial ventilation mode. The median duration of ventilation in children initially treated with HFO was 17 days (range 1-199), compared to 11 days (range 0-741) in children treated with conventional ventilation $(\mathrm{p}<0.001)$. 
Table 3. Univariate analyses of baseline variables for patients born between 2001 and 2006 who had BPD and/or had died by day 30 $(\mathrm{n}=1,116$, missing data $=75)$

\begin{tabular}{|c|c|c|c|}
\hline Variable & $\begin{array}{l}\text { BPD and/or death } \\
\text { by day } 30\end{array}$ & $\%$ & $\mathrm{p}$ value \\
\hline Gender & & & 0.160 \\
\hline Male & $649 / 1,192$ & 58 & \\
\hline Female & $467 / 809$ & 58 & \\
\hline Volume of center & & & 0.085 \\
\hline High & $521 / 900$ & 58 & \\
\hline Low & $595 / 1,103$ & 54 & \\
\hline Birth in ECMO center & & & 0.006 \\
\hline Yes & $1,040 / 1,836$ & 57 & \\
\hline No & $76 / 167$ & 46 & \\
\hline Birth location & & & $<0.001$ \\
\hline Inborn & $534 / 812$ & 66 & \\
\hline Outborn & $582 / 1,189$ & 49 & \\
\hline Method of delivery & & & $<0.001$ \\
\hline Cesarean section & $496 / 807$ & 61 & \\
\hline Vaginal delivery & $499 / 985$ & 51 & \\
\hline Prenatal diagnosis & & & $<0.001$ \\
\hline Yes & $802 / 1,204$ & 67 & \\
\hline No & $310 / 794$ & 39 & \\
\hline Cardiac abnormality & & & $<0.001$ \\
\hline Yes & $242 / 312$ & 78 & \\
\hline No & $874 / 1,690$ & 52 & \\
\hline Chromosomal abnormality & & & $<0.001$ \\
\hline Yes & $78 / 87$ & 90 & \\
\hline No & $1,037 / 1,915$ & 54 & \\
\hline Other abnormality ${ }^{1}$ & & & 1.000 \\
\hline Yes & $94 / 169$ & 56 & \\
\hline No & $1,022 / 1,834$ & 56 & \\
\hline Side of defect & & & $<0.001$ \\
\hline Left & $879 / 1,667$ & 53 & \\
\hline Right & $229 / 328$ & 70 & \\
\hline Initial ventilation mode & & & $<0.001$ \\
\hline HFO & $460 / 632$ & 73 & \\
\hline $\mathrm{CMV}$ & $564 / 1,233$ & 46 & \\
\hline Continuous variables & Median (range) & & $\mathrm{p}$ value \\
\hline Gestational age, weeks & $6(0-10)$ & & $<0.001$ \\
\hline Birth weight, kg & $2.93(0.57-4.80)$ & & $<0.001$ \\
\hline Apgar score at $5 \mathrm{~min}$ & $38(23-42)$ & & $<0.001$ \\
\hline
\end{tabular}

Numbers do not always add up to 1,116 because of missing data. $\mathrm{CMV}=$ Conventional mechanical ventilation.

${ }^{1}$ Other abnormality is classified as a congenital anomaly other than congenital heart disease or a chromosomal abnormality.

Differences in baseline patient characteristics between patients who initially received HFO or conventional ventilation are presented in table 2. Patients who received $\mathrm{HFO}$ as the initial ventilation mode were significantly more often prenatally diagnosed ( $\mathrm{p}<0.001$ ), inborn (i.e. born in a tertiary clinic; $\mathrm{p}<0.001$ ) and born in an ECMO center $(p<0.001)$, had significantly more other abnormalities $(\mathrm{p}=0.031)$ and had a significantly lower median birth weight $(\mathrm{p}<0.001)$ and Apgar score at $5 \mathrm{~min}(\mathrm{p}<$ 0.001).

Patients who received initial treatment with $\mathrm{HFO}$ had BPD and/or died by day 30 significantly more often than patients who received initial treatment with conventional ventilation ( $p<0.001$; data shown in tables 3 and 4$)$.

Of the infants who initially received HFO, 39\% ( $\mathrm{n}=$ 260/674) underwent an ECMO procedure, compared with $23 \%(n=296 / 1,262)$ of the infants who initially received conventional ventilation $(\mathrm{p}<0.001)$. In total, 526 patients who initially received HFO and 1,100 patients who initially received conventional ventilation underwent a surgical repair. Of those patients, $64 \%$ of the patients who were initially treated with HFO ( $\mathrm{n}=336 / 524$, missing data $=2$ ) underwent a patch repair, as opposed to primary closure, compared with $40 \%$ ( $\mathrm{n}=441 / 1,098$, missing data $=2$ ) of patients treated with conventional ventilation as initial ventilation mode $(\mathrm{p}<0.001)$.

\section{Multivariate Analysis}

The univariate analyses of baseline variables for BPD and/or mortality by day 30 are presented in table 3. Separate univariate analyses for BPD and mortality by day 30 are presented in table 4 . Baseline variables that were significant were entered into multiple logistic regression analyses for all 3 outcome measures. Variables regarding surgical repair and ECMO therapy were not entered into the multivariate analyses, because we only included those variables that were known at baseline.

As data on the method of delivery were missing for 223 patients, we excluded this variable from the multivariate analyses. Birth weight and gestational age were both significant in the univariate analyses, but due to their high correlation with each other, only gestational age was added to the multivariate analysis.

The baseline variables location of birth (in- or outborn, i.e. not in a tertiary clinic), birth in an ECMO center (yes or no), prenatal diagnosis, cardiac abnormality, chromosomal abnormality, side of the defect (left or right side), Apgar score at $5 \mathrm{~min}$, the initial mode of ventilation and gestational age were all entered in the multivariate analyses for early mortality and BPD.

The results of the final multivariate analyses are shown in tables 5, 6 and 7. A lower gestational age, a cardiac anomaly, a chromosomal anomaly, a prenatal diagnosis, a right-sided defect, a lower Apgar score at $5 \mathrm{~min}$ and 
Table 4. Univariate analyses of baseline variables for patients born between 2001 and 2006 who had BPD $(\mathrm{n}=624)$ or who had died by day $30(\mathrm{n}=492)$

\begin{tabular}{|c|c|c|c|c|c|c|}
\hline Variable & $\mathrm{BPD}$ & $\%$ & $\mathrm{p}$ value & Death by day 30 & $\%$ & $\mathrm{p}$ value \\
\hline Gender & & & 0.420 & & & 0.150 \\
\hline Male & $370 / 913$ & 41 & & $279 / 1,235$ & 23 & \\
\hline Female & $254 / 596$ & 43 & & $213 / 841$ & 25 & \\
\hline Volume of center & & & 0.071 & & & 0.398 \\
\hline High & $303 / 690$ & 44 & & $276 / 1,132$ & 24 & \\
\hline Low & $321 / 821$ & 39 & & $236 / 946$ & 25 & \\
\hline Birth in ECMO center & & & $<0.001$ & & & 0.016 \\
\hline Yes & $601 / 1,397$ & 43 & & $439 / 1,910$ & 23 & \\
\hline No & $23 / 114$ & 20 & & $53 / 168$ & 32 & \\
\hline Birth location & & & $<0.001$ & & & $<0.001$ \\
\hline Inborn & $260 / 538$ & 48 & & $274 / 837$ & 33 & \\
\hline Outborn & $364 / 971$ & 37 & & $218 / 1,239$ & 18 & \\
\hline Method of delivery & & & 0.007 & & & $<0.001$ \\
\hline Cesarean section & $255 / 566$ & 45 & & $241 / 834$ & 29 & \\
\hline Vaginal delivery & $294 / 780$ & 38 & & $205 / 1,021$ & 20 & \\
\hline Prenatal diagnosis & & & $<0.001$ & & & $<0.001$ \\
\hline Yes & $434 / 836$ & 52 & & $368 / 1,246$ & 30 & \\
\hline No & $188 / 672$ & 28 & & $122 / 827$ & 15 & \\
\hline Cardiac abnormality & & & $<0.001$ & & & $<0.001$ \\
\hline Yes & $127 / 197$ & 64 & & $115 / 322$ & 36 & \\
\hline No & $497 / 1,313$ & 38 & & $377 / 1,755$ & 21 & \\
\hline Chromosomal abnormality & & & $<0.001$ & & & $<0.001$ \\
\hline Yes & $23 / 32$ & 72 & & $55 / 89$ & 62 & \\
\hline No & $601 / 1,479$ & 41 & & $436 / 1,988$ & 22 & \\
\hline Other abnormality ${ }^{1}$ & & & 0.445 & & & 0.241 \\
\hline Yes & $46 / 121$ & 38 & & $48 / 176$ & 27 & \\
\hline No & $578 / 1,390$ & 42 & & $444 / 1,902$ & 23 & \\
\hline Side of defect & & & $<0.001$ & & & 0.001 \\
\hline Left & $497 / 1,285$ & 39 & & $382 / 1,735$ & 22 & \\
\hline Right & $127 / 226$ & 56 & & $102 / 335$ & 30 & \\
\hline Initial ventilation mode & & & $<0.001$ & & & $<0.001$ \\
\hline $\mathrm{HFO}$ & $229 / 401$ & 57 & & $231 / 674$ & 34 & \\
\hline CMV & $346 / 1,015$ & 34 & & $218 / 1,262$ & 17 & \\
\hline Continuous variables & Median (range) & & & Median (range) & & \\
\hline Gestational age, weeks & $38(23-42)$ & & $<0.001$ & $38(26-42)$ & & $<0.001$ \\
\hline Birth weight, kg & $3.00(0.64-4.8)$ & & $<0.001$ & $2.79(0.57-4.48)$ & & $<0.001$ \\
\hline Apgar score at $5 \mathrm{~min}$ & $7(0-10)$ & & $<0.001$ & $6(0-9)$ & & $<0.001$ \\
\hline
\end{tabular}

Numbers do not always add up to 624 and 492 because of missing data. CMV = Conventional mechanical ventilation.

${ }^{1}$ Other abnormality is classified as a congenital anomaly other than congenital heart disease or a chromosomal abnormality.

HFO as initial ventilation mode were associated with a higher risk of BPD and/or death by day 30 . Having a chromosomal anomaly was also associated with early mortality, but not with BPD. Additionally, being inborn was associated with a higher risk of mortality by day 30 , and being outborn was associated with a higher risk of BPD.
Although we did not include variables that were not known at baseline, we did test for various interactions between these variables and the baseline variables. In this regard, we found an interaction between the need for ECMO treatment and the initial mode of ventilation in the multivariate analyses for BPD and/or death by day 30 
Table 5. Multivariate logistic regression analysis of BPD and/or death by day $30(n=1,686)$

\begin{tabular}{lccr}
\hline Variable & OR & $95 \%$ CI & p value \\
\hline Gestational age in weeks & 0.84 & $0.81-0.90$ & $<0.001$ \\
Cardiac abnormality & 2.62 & $1.85-3.72$ & $<0.001$ \\
Chromosomal abnormality & 3.04 & $1.42-6.51$ & 0.004 \\
Prenatal diagnosis & 3.90 & $3.00-5.00$ & $<0.001$ \\
Right-sided defect & 2.76 & $1.96-3.89$ & $<0.001$ \\
Apgar score at 5 min & 0.61 & $0.57-0.65$ & $<0.001$ \\
HFO as initial ventilation mode & 2.53 & $1.95-3.27$ & $<0.001$ \\
\hline
\end{tabular}

Nonsignificant variables in the multivariate analysis: birth in ECMO center (odds ratio 1.39, 95\% confidence interval 0.80-2.44; $\mathrm{p}=0.244$ ) and location of birth (odds ratio $1.1,95 \%$ confidence interval $0.83-1.46 ; \mathrm{p}=0.487)$. $\mathrm{OR}=$ Odds ratio; $\mathrm{CI}=$ confidence interval.

Table 7. Multivariate logistic regression analysis for mortality by day $30(\mathrm{n}=1,749)$

\begin{tabular}{lccr}
\hline Variable & OR & $95 \%$ CI & p value \\
\hline Gestational age in weeks & 0.87 & $0.83-0.92$ & $<0.001$ \\
Cardiac abnormality & 1.54 & $1.11-2.14$ & 0.010 \\
Chromosomal abnormality & 4.49 & $2.63-7.67$ & $<0.001$ \\
Inborn & 1.76 & $1.30-2.38$ & $<0.001$ \\
Prenatal diagnosis & 1.80 & $1.28-2.02$ & $<0.001$ \\
Right-sided defect & 1.88 & $1.35-2.63$ & $<0.001$ \\
Apgar score at 5 min & 0.68 & $0.64-0.73$ & $<0.001$ \\
HFO as initial ventilation mode & 1.85 & $1.42-2.41$ & $<0.001$ \\
\hline
\end{tabular}

Nonsignificant variable in the multivariate analysis: birth in ECMO center (odds ratio 0.71, 95\% confidence interval 0.37-1.34; $\mathrm{p}=0.286)$. OR = Odds ratio; $\mathrm{CI}=$ confidence interval.

and BPD alone. This revealed that in patients who underwent an ECMO procedure, the initial mode of ventilation was no longer associated with these outcome measures.

Also, we found an interaction between the location of birth and HFO as initial ventilation mode. In patients who were born outside a tertiary clinic, HFO was still associated with a higher risk of BPD and/or death by day 30 and BPD alone. In patients who were born in a tertiary clinic, HFO gave a slightly higher risk of BPD and/or death by day 30 and BPD alone. However, this was not significant because the confidence intervals overlapped.

We did not find any interactions between birth in an ECMO center, the volume of the center and the initial
Table 6. Multivariate logistic regression analysis for BPD ( $\mathrm{n}=$ 1,293)

\begin{tabular}{lccr}
\hline Variable & OR & $95 \%$ CI & p value \\
\hline Gestational age in weeks & 0.87 & $0.82-0.92$ & $<0.001$ \\
Cardiac abnormality & 2.42 & $1.85-3.67$ & $<0.001$ \\
Inborn & 0.70 & $0.52-0.95$ & 0.023 \\
Prenatal diagnosis & 4.27 & $3.05-5.80$ & $<0.001$ \\
Right-sided defect & 2.51 & $1.73-3.64$ & $<0.001$ \\
Apgar score at 5 min & 0.66 & $0.61-0.71$ & $<0.001$ \\
HFO as initial ventilation mode & 2.29 & $1.73-3.04$ & $<0.001$ \\
\hline
\end{tabular}

Nonsignificant variables in the multivariate analysis: birth in ECMO center (odds ratio 1.81, 95\% confidence interval 0.94-3.48; $\mathrm{p}=0.074$ ) and having a chromosomal abnormality (odds ratio $1.37,95 \%$ confidence interval $0.57-3.26 ; \mathrm{p}=0.480)$. OR = Odds ratio; $\mathrm{CI}=$ confidence interval.

ventilation mode. Also, we did not find any variables that modified the effect of HFO in the analysis for early mortality.

\section{Discussion}

In this study, $56 \%$ of all the infants included had either died or met the criteria for BPD at day 30. In survivors of $\mathrm{CDH}, \mathrm{BPD}$, with a prevalence of $41 \%$, remains an important clinical issue. Moreover, the prevalence of BPD and/ or early mortality remained constant over the years of the study period, despite promising advances in neonatal care and urgent reports from centers around the world. Unexpectedly, this study showed that initial ventilatory treatment with HFO was associated with worse postnatal outcome.

We can propose several causes for the high prevalence of BPD. Firstly, these children's hypoplastic lungs may be more susceptible to oxygen toxicity than the lungs of other newborns with respiratory distress [12]. Moreover, maldevelopment of the pulmonary vasculature may contribute to pulmonary hypertension, which in itself increases morbidity and mortality in BPD [29]. Thirdly, the asymmetry of the lungs may result in areas of differential compliance and the subsequent risk of overexpansion of the alveoli $[12,13]$. Fourthly, although centers mostly use gentle ventilation strategies nowadays, aggressive ventilation strategies with high peak inspiratory pressures cannot always be avoided. Subsequent volutrauma, barotrauma and atelectrauma may contribute to significant 
pulmonary injury, including diffuse alveolar damage, hyaline membrane formation and intra-alveolar hemorrhage $[23,30]$.

This study suggests that $\mathrm{HFO}$ as the initial ventilation mode is a risk factor for BPD and/or mortality by day 30 and for BPD and mortality separately. This was a somewhat surprising finding because previous retrospective and observational studies indicated that HFO as the initial ventilation mode might be an effective method to increase survival and reduce BPD in newborns with $\mathrm{CDH}$ $[21,22,24]$. It was thought to ameliorate ventilation-induced lung injury by promoting uniform lung inflation, reducing barotrauma and suppressing inflammatory mediators [23, 30-33]. On the other hand, HFO might well cause lung hyperinflation. The resultant higher alveolar and mean airway pressures would then raise the risk of pulmonary barotrauma and hemodynamic instability, due to adverse effects on venous return and pulmonary vascular resistance [23].

A possible explanation for the association between HFO as the initial ventilation mode and BPD as well as early mortality might be that the infants who initially received $\mathrm{HFO}$ were more severely ill from the start. Compared with those patients who received conventional ventilation initially, patients who received $\mathrm{HFO}$ as initial treatment had a significantly lower Apgar score at $5 \mathrm{~min}$ and a lower birth weight. Patients who received HFO were more often inborn and prenatally diagnosed compared with infants who received conventional ventilation. HFO was also associated with a significantly longer duration of ventilation compared with conventional ventilation. Furthermore, patients who received initial treatment with HFO underwent an ECMO procedure more often. Moreover, they more often had a patch repair, which might be associated with a larger defect size and more severe pulmonary hypoplasia. Therefore, we may speculate that these infants' condition was worse than that of infants on conventional ventilation from the start.

In this regard, it is unfortunate that some variables that might have given an indication of the severity of disease could not be included in the multivariate analyses because they were not known at baseline. However, we did test for various interactions between variables. In this regard, we found that in patients who underwent an ECMO procedure, the initial mode of ventilation was no longer associated with BPD and/or death by day 30 and BPD alone. Also, HFO gave only a slightly higher risk of BPD and/or death by day 30 and BPD alone in patients who were born in a tertiary clinic. Moreover, we did not find any variables that modified the effect of $\mathrm{HFO}$ in the analysis for early mortality. Baseline data on prenatal predictors of outcome, such as the lung-to-head ratio, were not available. It may, for example, be speculated that fetuses with a lower lung-to-head ratio and a possible worse outcome may have been treated initially with HFO.

A right-sided defect was associated with a higher risk of BPD and/or early mortality and BPD and early mortality separately. This is in line with previous studies, which reported a higher risk of mortality and worse outcome in patients with right-sided defects [34, 35].

Furthermore, a prenatal diagnosis was another important risk factor for BPD and/or early mortality and BPD and early mortality separately. Infants who are diagnosed prenatally are more likely to have more obvious anomalies and a more severe herniation visible on ultrasound, which may explain this higher risk of a worse outcome. However, prenatal detection of the diaphragmatic defect in infants with $\mathrm{CDH}$ may be dependent on the quality of obstetric care and prenatal screening.

A low Apgar score at $5 \mathrm{~min}$ of life was also associated with a higher risk of a worse outcome. This is in line with a previous study by the CDH Study Group, which reported that the Apgar score at 5 min predicted mortality in newborns with $\mathrm{CDH}$ [36]. Furthermore, a cardiac abnormality, a chromosomal anomaly and a lower gestational age were also associated with worse outcome.

Being inborn, i.e. in a tertiary clinic, was a risk factor for early mortality in this study. This may be explained by the fact that mortality is not always reported in pregnancy terminations, stillbirths and outborn children who die shortly after birth [37]. As a consequence, the mortality rate for inborn children with $\mathrm{CDH}$ may be relatively higher. However, it must be taken into account that the study centers in the CDH Registry use different referral policies.

This study did not show an association between the volume of the center and postnatal outcome. However, a previous study reported higher survival rates in high-volume centers, defined as more than 6 patients with $\mathrm{CDH}$ admitted per year [38]. This difference may be explained by the fact that we used a different cutoff to define the volume of the center. Also, no association was found between postnatal outcome and birth in an ECMO center. In the multivariate analysis, no associations were found between birth in an ECMO center, birth in a high-volume center and the initial ventilation mode. More specific data on the type of center and the treatment protocols they used are lacking, since all centers are anonymously coded in the CDH Registry. Differences between the var- 
ious centers may therefore still play a role in outcome in infants with $\mathrm{CDH}$, although we were not able to find such an association in this study.

This study showed that gender was not a risk factor for worse outcome in newborns with $\mathrm{CDH}$. Studies in preterm infants reported boys to be at higher risk for BPD and mortality in general $[39,40]$. As newborns with $\mathrm{CDH}$ are usually born at term, the above-mentioned association reported for premature infants may not be fully applicable to them.

Although ECMO could not be included in the multivariate analysis, because it is not a baseline characteristic, ECMO was associated with a higher risk of BPD and early mortality in univariate analyses. Patients with $\mathrm{CDH}$ who need ECMO therapy are likely to have severe pulmonary hypoplasia and pulmonary hypertension, resulting in a higher risk of worse outcome. Mortality after an ECMO procedure was 51\%, which is comparable to previous studies and data from the Extracorporeal Life Support Organization registry [41, 42]. The role of ECMO in the treatment of infants with $\mathrm{CDH}$ is still unclear [43]. However, in nonrandomized trials, ECMO has been reported to improve survival in infants with $\mathrm{CDH}[44,45]$.

This is the first study to describe chronic lung disease and its risk factors in a large number of patients with $\mathrm{CDH}$. However, its possible limitations should not go unmentioned. For one, some important data could not be determined, such as disease severity, pulmonary hypertension, the position of the liver, the severity of BPD and prenatal predictors of outcome. Therefore, additional research should be performed taking into account the full spectrum of the disease. Moreover, patients who received HFO underwent an ECMO procedure more often, and the association between BPD and/or death by day 30 and BPD alone and the initial ventilation mode was not shown in infants who received ECMO therapy. Therefore, confounding by indication may have biased our results. Furthermore, selection bias could have occurred because only data from hospitals participating in the CDH Study Group were retrieved. In addition, these hospitals used different treatment protocols and referral policies, which may have influenced outcomes. In this regard, oxygen dependency was not defined according to standard practice in our study centers. A previous study by Walsh et al. [46] reported a lower incidence of BPD if oxygen dependency was confirmed by a room air challenge test. Since data on room air challenge tests were not available in our study, our results may have been biased.

\section{Conclusion}

BPD and mortality in newborns with $\mathrm{CDH}$ remain important problems, despite improvements in neonatal care. Moreover, BPD may lead to long-term pulmonary morbidity. HFO has been heralded as a promising ventilation treatment to reduce mortality and pulmonary morbidity in $\mathrm{CDH}$ newborns. However, in the present study, initial ventilation treatment with $\mathrm{HFO}$ was associated with a higher risk of a worse outcome. Nonetheless, the results of this study must be interpreted with caution, because selection bias and confounding by indication may have occurred. Therefore, further prospective studies are needed to study risk factors and optimal ventilation strategies in children with $\mathrm{CDH}$. In addition, standardized treatment protocols and follow-up guidelines, such as those developed by the American Academy of Pediatrics in 2008, should be implemented as crucial ways to improve healthcare in children with $\mathrm{CDH}$ [15]. This calls for extensive collaboration between centers with expertise in the treatment of newborns with $\mathrm{CDH}$, such as the CDH Euro-Consortium, which recently initiated the VICI trial, a randomized controlled trial on ventilation strategies in infants with $\mathrm{CDH}$ (www.vicitrial.com).

\section{Appendix}

\section{Writing Committee}

The members of the Congenital Diaphragmatic Hernia Study Group writing committee are as follows: Lieke van den Hout, MD, Irwin Reiss, $\mathrm{MD}, \mathrm{PhD}$, and Dick Tibboel, $\mathrm{MD}, \mathrm{PhD}$ (Intensive Care and Department of Pediatric Surgery, Erasmus MC - Sophia, Rotterdam, The Netherlands), Janine Felix, MD, PhD (Department of Epidemiology, Erasmus MC, Rotterdam, The Netherlands), Wim Hop, MSc, PhD (Department of Biostatistics, Erasmus MC, Rotterdam, The Netherlands), Pamela A. Lally, MD, and Kevin P. Lally, MD, MSc (Department of Pediatric Surgery, University of Texas Medical School and Children's Memorial Hermann Hospital, Houston, Tex., USA).

\section{Contributing Centers}

The following centers contributed to the CDH Registry: Arnold Palmer Hospital for Women and Children (Orlando, Fla., USA); Astrid Lindgren Children's Hospital (Stockholm, Sweden); Central Hospital Aichi Prefectural Colony (Kasugai, Japan); Children's Hospital at Carolinas Medical Center (Charlotte, N.C., USA); Children's Hospital Boston (Boston, Mass., USA); Children's Hospital of Akron (Akron, Ohio, USA); Children's Hospital of Alabama (Birmingham, Ala., USA); Children's Hospital of Illinois (Peoria, Ill., USA); Children's Hospital of Los Angeles (Los Angeles, Calif., USA); Children's Hospital of Minneapolis (Minneapolis, Minn., USA); Children's Hospital of Oakland (Oakland, Calif., USA); Children's Hospital of Oklahoma (Oklahoma City, 
Okla., USA); Children's Hospital of Wisconsin (Milwaukee, Wisc., USA); Cincinnati Children's Hospital Medical Center (Cincinnati, Ohio, USA); Cleveland Clinic Foundation-Children's Hospital (Cleveland, Ohio, USA); Columbus Children's Hospital (Columbus, Ohio, USA); DeVos Children's Hospital (Grand Rapids, Mich., USA); Emory University (Atlanta, Ga., USA); Hershey Medical Center (Hershey, Pa., USA); James Whitcomb Riley Children's Hospital (Indianapolis, Ind., USA); Kosair Children's Hospital (Louisville, Ky., USA); Legacy Emanuel Children's Hospital (Portland, Oreg., USA); Loma Linda University Children's Hospital (Loma Linda, Calif., USA); Lucile Salter Packard Children's Hospital (Palo Alto, Calif., USA); Mattel Children's Hospital at UCLA (Los Angeles, Calif., USA); Medical College of Georgia (Augusta, Ga., USA); Children's Memorial Hermann Hospital (Houston, Tex., USA); Miami Valley Hospital (Dayton, Ohio, USA); National Center for Child Health and Development (Tokyo, Japan); Ospedale Pediatrico Bambino Gesù (Rome, Italy); Ospedale Riunite Bergamo (Bergamo, Italy); Osaka University Graduate School of Medicine (Osaka, Japan); Phoenix Children's Hospital (Phoenix, Ariz., USA); Rainbow Babies \& Children's Hospital (Cleveland, Ohio, USA); Royal Alexandra Hospital (Edmonton, Alta., Canada), Royal Children's Hospital Parkville
(Melbourne, Vic., Australia); Royal Hospital for Sick Children (Glasgow, Scotland); San Diego Children's Hospital (San Diego, Calif., USA); Santa Rosa Children's Hospital (San Antonio, Tex., USA); Shands Children's Hospital/University of Florida (Gainesville, Fla., USA); Erasmus MC - Sophia (Rotterdam, The Netherlands); St. Francis Children's Hospital (Tulsa, Okla., USA); St. Joseph's Hospital and Medical Center (Phoenix, Ariz., USA); Strong Children's Hospital (Rochester, N.Y., USA); Sydney Children's Hospital (Sydney, N.S.W., Australia); Hospital for Sick Children (Toronto, Ont., Canada); University of Michigan Medical Center (Ann Arbor, Mich., USA); University of Nebraska Medical Center (Omaha, Nebr., USA); University of Texas Medical Branch (Galveston, Tex., USA); University of Virginia Health System (Charlottesville, Va., USA), and Vanderbilt Children's Hospital (Nashville, Tenn., USA).

\section{Acknowledgments}

We thank D. Bohn for critical revision of this article and J. Hagoort for editorial assistance.

\section{References}

1 Lally KP: Congenital diaphragmatic hernia. Curr Opin Pediatr 2002;14:486-490.

2 Wung JT, Sahni R, Moffitt ST, Lipsitz E, Stolar CJ: Congenital diaphragmatic hernia: survival treated with very delayed surgery, spontaneous respiration, and no chest tube. J Pediatr Surg 1995;30:406-409.

-3 Reyes C, Chang LK, Waffarn F, Mir H, Warden MJ, Sills J: Delayed repair of congenital diaphragmatic hernia with early high-frequency oscillatory ventilation during preoperative stabilization. J Pediatr Surg 1998;33: 1010-1014, discussion 1014-1016.

-4 Frenckner B, Ehrén H, Granholm T, Lindén V, Palmér K: Improved results in patients who have congenital diaphragmatic hernia using preoperative stabilization, extracorporeal membrane oxygenation, and delayed surgery. J Pediatr Surg 1997;32:1185-1189.

-5 Boloker J, Bateman DA, Wung JT, Stolar CJ: Congenital diaphragmatic hernia in 120 infants treated consecutively with permissive hypercapnea/spontaneous respiration/elective repair. J Pediatr Surg 2002;37:357-366.

6 Kays DW, Langham MR Jr, Ledbetter DJ, Talbert JL: Detrimental effects of standard medical therapy in congenital diaphragmatic hernia. Ann Surg 1999;230:340-348, discussion 348-351.

$\checkmark 7$ Robinson PD, Fitzgerald DA: Congenital diaphragmatic hernia. Paediatr Respir Rev 2007;8:323-334, quiz 334-335.
-8 Downard CD, Jaksic T, Garza JJ, Dzakovic A, Nemes L, Jennings RW, Wilson JM: Analysis of an improved survival rate for congenital diaphragmatic hernia. J Pediatr Surg 2003; 38:729-732

-9 Trachsel D, Selvadurai H, Bohn D, Langer JC, Coates AL: Long-term pulmonary morbidity in survivors of congenital diaphragmatic hernia. Pediatr Pulmonol 2005;39: 433-439.

$>10$ Ijsselstijn H, Tibboel D, Hop WJ, Molenaar JC, de Jongste JC: Long-term pulmonary sequelae in children with congenital diaphragmatic hernia. Am J Respir Crit Care Med 1997;155:174-180.

11 Dotta A, Palamides S, Braguglia A, Crescenzi F, Ronchetti MP, Calzolari F, Iacobelli BD, Bagolan P, Corchia C, Orzalesi M: Lung volumes and distribution of ventilation in survivors to congenital diaphragmatic hernia $(\mathrm{CDH})$ during infancy. Pediatr Pulmonol 2007;42:600-604.

12 Bos AP, Hussain SM, Hazebroek FW, Tibboel D, Meradji M, Molenaar JC: Radiographic evidence of bronchopulmonary dysplasia in high-risk congenital diaphragmatic hernia survivors. Pediatr Pulmonol 1993;15: 231-234.

13 Vanamo K, Rintala R, Sovijärvi A, Jääskeläinen J, Turpeinen M, Lindahl $\mathrm{H}$, Louhimo I: Long-term pulmonary sequelae in survivors of congenital diaphragmatic defects. J Pediatr Surg 1996;31:1096-1099, discussion 1099-1100.
14 Muratore, CS, Kharasch, V, Lund, DP, Sheils C, Friedman S, Brown C, Utter S, Jaksic T, Wilson JM: Pulmonary morbidity in 100 survivors of congenital diaphragmatic hernia monitored in a multidisciplinary clinic. J Pediatr Surg 2001;36:133-140.

15 Lally KP, Engle W: Postdischarge follow-up of infants with congenital diaphragmatic hernia. Pediatrics 2008;121:627-632.

16 Baraldi E, Filippone M: Chronic lung disease after premature birth. N Engl J Med 2007; 357:1946-1955.

$\checkmark 17$ Allen J, Zwerdling R, Ehrenkranz R, Gaultier C, Geggel R, Greenough A, Kleinman R, Klijanowicz A, Martinez F, Ozdemir A, Panitch HB, Nickerson B, Stein MT, Tomezsko J, Van Der Anker J; American Thoracic Society: Statement on the care of the child with chronic lung disease of infancy and childhood. Am J Respir Crit Care Med 2003;168: 356-396.

18 Bagolan P, Morini F: Long-term follow up of infants with congenital diaphragmatic hernia. Semin Pediatr Surg 2007;16:134-144.

19 Wung JT, James LS, Kilchevsky E, James E: Management of infants with severe respiratory failure and persistence of the fetal circulation, without hyperventilation. Pediatrics 1985;76:488-494

20 van den Hout L, Sluiter I, Gischler S, De Klein A, Rottier R, Ijsselstijn H, Reiss I, Tibboel D: Can we improve outcome of congenital diaphragmatic hernia? Pediatr Surg Int 2009;25:733-743. 
-21 Ng GY, Derry C, Marston L, Choudhury M, Holmes K, Calvert SA: Reduction in ventilator-induced lung injury improves outcome in congenital diaphragmatic hernia? Pediatr Surg Int 2008;24:145-150.

-22 Migliazza L, Bellan C, Alberti D, Auriemma A, Burgio G, Locatelli G, Colombo A: Retrospective study of 111 cases of congenital diaphragmatic hernia treated with early highfrequency oscillatory ventilation and presurgical stabilization. J Pediatr Surg 2007;42: 1526-1532.

-23 Logan JW, Cotten CM, Goldberg RN, Clark RH: Mechanical ventilation strategies in the management of congenital diaphragmatic hernia. Semin Pediatr Surg 2007;16:115-125.

-24 Cacciari A, Ruggeri G, Mordenti M, Ceccarelli PL, Baccarini E, Pigna A, Gentili A: High-frequency oscillatory ventilation versus conventional mechanical ventilation in congenital diaphragmatic hernia. Eur J Pediatr Surg 2001;11:3-7.

-25 Peetsold MG, Heij HA, Kneepkens CM, Nagelkerke AF, Huisman J, Gemke RJ: The long-term follow-up of patients with a congenital diaphragmatic hernia: a broad spectrum of morbidity. Pediatr Surg Int 2009;25: $1-17$.

-26 Tsao K, Lally KP: The Congenital Diaphragmatic Hernia Study Group: a voluntary international registry. Semin Pediatr Surg 2008;17:90-97.

$\checkmark 27$ Bennett AJ, Driver CP, Munro M: Bilateral congenital diaphragmatic hernia. Pediatr Surg Int 2005;21:739-741.

-28 Jobe AH, Bancalari E: Bronchopulmonary dysplasia. Am J Respir Crit Care Med 2001; 163:1723-1729.

29 Thebaud B: Angiogenesis in lung development, injury and repair: implications for chronic lung disease of prematurity. Neonatology 2007;91:291-297.

-30 Sakurai Y, Azarow K, Cutz E, Messineo A, Pearl R, Bohn D: Pulmonary barotrauma in congenital diaphragmatic hernia: a clinicopathological correlation. J Pediatr Surg 1999; 34:1813-1817.
31 Bhuta T, Clark RH, Henderson-Smart DJ: Rescue high frequency oscillatory ventilation vs conventional ventilation for infants with severe pulmonary dysfunction born at or near term. Cochrane Database Syst Rev 2001;(1):CD002974.

32 deLemos R, Yoder B, McCurnin D, Kinsella J, Clark R, Null D: The use of high-frequency oscillatory ventilation (HFOV) and extracorporeal membrane oxygenation (ECMO) in the management of the term/near term infant with respiratory failure. Early Hum Dev 1992;29:299-303.

33 Henderson-Smart DJ, Cools F, Bhuta T, Offringa $\mathrm{M}$ : Elective high frequency oscillatory ventilation versus conventional ventilation for acute pulmonary dysfunction in preterm infants. Cochrane Database Syst Rev 2007;(3):CD000104

34 Skari H, Bjornland K, Frenckner B, Friberg LG, Heikkinen M, Hurme T, Loe B, Mollerlokken G, Nielsen $\mathrm{OH}$, Qvist N, Rintala R, Sandgren K, Wester T, Emblem R: Congenital diaphragmatic hernia in Scandinavia from 1995 to 1998: predictors of mortality. J Pediatr Surg 2002;37:1269-1275.

35 Fisher JC, Jefferson RA, Arkovitz MS, Stolar CJ: Redefining outcomes in right congenital diaphragmatic hernia. J Pediatr Surg 2008; 43:373-379.

36 Estimating disease severity of congenital diaphragmatic hernia in the first 5 minutes of life. The Congenital Diaphragmatic Hernia Study Group. J Pediatr Surg 2001;36:141-145.

- 37 Brownlee EM, Howatson AG, Davis CF, Sabharwal AJ: The hidden mortality of congenital diaphragmatic hernia: a 20 -year review. J Pediatr Surg 2009;44:317-320.

38 Grushka JR, Laberge JM, Puligandla P, Skarsgard ED: Effect of hospital case volume on outcome in congenital diaphragmatic hernia: the experience of the Canadian Pediatric Surgery Network. J Pediatr Surg 2009; 44:873-876.

39 Ambalavanan N, Van Meurs KP, Perritt R, Carlo WA, Ehrenkranz RA, Stevenson DK, Lemons JA, Poole WK, Higgins RD; NICHD Neonatal Research Network, Bethesda, MD Predictors of death or bronchopulmonary dysplasia in preterm infants with respiratory failure. J Perinatol 2008;28:420-426.
40 Lemons JA, Bauer CR, Oh W, Korones SB, Papile LA, Stoll BJ, Verter J, Temprosa M, Wright LL, Ehrenkranz RA, Fanaroff AA, Stark A, Carlo W, Tyson JE, Donovan EF, Shankaran S, Stevenson DK: Very low birth weight outcomes of the National Institute of Child health and human development neonatal research network, January 1995 through December 1996. NICHD Neonatal Research Network. Pediatrics 2001;107:E1.

41 Guner YS, Khemani RG, Qureshi FG, Wee CP, Austin MT, Dorey F, Rycus PT, Ford HR, Friedlich P, Stein JE: Outcome analysis of neonates with congenital diaphragmatic hernia treated with venovenous vs venoarterial extracorporeal membrane oxygenation. J Pediatr Surg 2009;44:1691-1701.

42 Conrad SA, Rycus PT, Dalton H: Extracorporeal Life Support Registry Report 2004. ASAIO J 2005;51:4-10.

43 Mugford M, Elbourne D, Field D: Extracorporeal membrane oxygenation for severe respiratory failure in newborn infants. CochraneDatabaseSystRev2008;(3):CD001340.

-44 Langham MR Jr, Krummel TM, Bartlett RH, Drucker DE, Tracy TF Jr, Toomasian JM, Greenfield LJ, Salzberg AM: Mortality with extracorporeal membrane oxygenation following repair of congenital diaphragmatic hernia in 93 infants. J Pediatr Surg 1987;22: 1150-1154.

45 Van Meurs KP, Newman KD, Anderson KD, Short BL: Effect of extracorporeal membrane oxygenation on survival of infants with congenital diaphragmatic hernia. J Pediatr 1990; 117:954-960.

-46 Walsh MC, Yao Q, Gettner P, Hale E, Collins M, Hensman A, Everette R, Peters N, Miller N, Muran G, Auten K, Newman N, Rowan G, Grisby C, Arnell K, Miller L, Ball B, McDavid G; National Institute of Child Health and Human Development Neonatal Research Network: Impact of a physiologic definition on bronchopulmonary dysplasia rates. Pediatrics 2004;114:1305-1311. 